\title{
THMs Precursor Removal Efficiency from Different Wastewater Treatment Technologies Effluents
}

\author{
Mohannad Qurie ${ }^{1,2}$, Loay Awad ${ }^{3}$, Amer Kanan $^{1 *}$ \\ ${ }^{1}$ Department of Environment and Earth Sciences, Al-Quds University, Palestine \\ ${ }^{2}$ Center for Chemical and Biological Analysis, Al-Quds University, Palestine \\ ${ }^{3}$ Basic Science Departement, Faculty of Engineering, Imam Abdulrahman bin Faisel University, Dammam, KSA \\ Email: lkawad@iau.edu.sa, *amerkanan@gmail.com
}

How to cite this paper: Qurie, M., Awad, L. and Kanan, A. (2018) THMs Precursor Removal Efficiency from Different Wastewater Treatment Technologies Effluents. Journal of Water Resource and Protection, 10, 637-653.

https://doi.org/10.4236/jwarp.2018.107036

Received: April 25, 2018

Accepted: July 6, 2018

Published: July 9, 2018

Copyright (c) 2018 by authors and Scientific Research Publishing Inc. This work is licensed under the Creative Commons Attribution International License (CC BY 4.0).

http://creativecommons.org/licenses/by/4.0/

\begin{abstract}
Treated wastewater is one of the critical practices of sustainable water management. In Palestinian authority region different wastewater technologies are used to produce variety of effluents that are potentially suitable for different purposes. In this study, these different treated wastewater effluents were characterized chemically, biologically, and physically. Results showed that some of these effluents neither comply with Palestinian nor with other global effluent discharge guidelines. Chemical reactivity of five different treated wastewater effluents with chlorine was measured by determining their chlorine demand and total trihalomethane formation potential (TTHMFP). Results showed that different wastewater effluents chemical reactivity with chlorine and TTHMFP is not only dependent on wastewater treatment technology but also is affected by original water source from which was the water emerged. In all cases, measured THMs superseded acceptable drinking water limits. This would indicate responsibility of high percentage of cancer, hepatic and renal diseases among the local people.
\end{abstract}

\section{Keywords}

Wastewater, Chlorination, Trihalomethane Formation Potential, Effluent, Hepatic Disease, Renal Disease, Cancer

\section{Introduction}

In Palestinian Authority region, the only fresh water resource available is groundwater. Water is a major concern since the region is one of the poorest regions in the world in terms of water resources availability. Presently the applica- 
tion of wastewater treatment started to increase and be of more concern as a conventional water resource for different acceptable uses. Palestinian Water Authority (PWA) and Palestinian Standards Institute (PSI) are cooperating in establishing proper environmental levels and standards for domestic wastewater effluent and for treatment plants effluents. Enforcement of such environmental guidelines and standards is important for both protecting Palestinian environment and ensuring that public health principles are considered when reusing these treated wastewater sources.

Disinfection (mostly chlorination) is usually used in water and wastewater treatment process to inactivate pathogenic microorganisms to prevent or at least to minimize the risk of waterborne, washed, based and other related diseases [1]. The disinfection of effluents (treated domestic wastewater) is also required before their utilization for different purposes such as agricultural irrigation, recharging groundwater through soil infiltration, or before disposal into large water bodies [2] [3].

Unfortunately, disinfection of drinking water or treated effluent with chlorine (as the most applicable disinfectant) comes with the formation of harmful carcinogenic and mutagenic disinfection by products (DBPs). The interaction of high load of organic and inorganic precursors enriches treated wastewater effluents causing the DBPs formation. THMs are the major class of DBPs and their presence is considered as an indicator for other DBPs occurrence such as haloacetic acids (HAAs) and total organic halides (TOX) [4]. There are four main THMs that are considered in different water guidelines and standards. These are chloroform $\left(\mathrm{CHCl}_{3}\right)$, bromodichloromethane $\left(\mathrm{CHBrCl}_{2}\right)$, chlorodibromomethane $\left(\mathrm{CHBr}_{2} \mathrm{Cl}\right)$ and bromoform $\left(\mathrm{CHBr}_{3}\right)$; the sum of these THMs is known as total THMs (TTHMs) [5]. The extent of chlorine demand and reactivity informing THMs is a function of organic precursor presence and characteristics [6]. The determination of TTHMs formed under controlled set of conditions in the presence of excess chlorine is called trihalomethane formation potential (THMFP). THMFP of treated wastewater (wastewater treatment plants effluents) were not investigated in Palestine.

The aim of this study is to investigate the potential formation of THMs from different wastewater treatment plant effluents using different treatment methods and technologies in Palestine. Treatment plants and treated wastewater samples will be characterized before the assessment of THMFP.

\section{Materials and Methods}

\subsection{Materials}

All chemicals were of analytical grade. Sodium hypochlorite solution (5\%) and N,N-diethyl-p-phenylenediamine (DPD) purchased from (Sigma, catalog no. 261513). Sodium phosphate (catalog no. 5778), Sodium citrate (catalog no. 54641), EDTA (catalog no. E9884), Phenol crystals (catalog no. p 5566), Sodium nitroprusside (catalog no. 0501), Sodium hydroxide (catalog no. 30620), Sodium 
hypochlorite (catalog no. 48481), Potassium dichromate (catalog no. P5271), Silver sulfate (catalog no. S-7638), Potassium nitrate (catalog no. 221295), Glutamic acid (catalog no. G1252), Glucose (catalog no. 8270), Ascorbic acid (catalog no. A92902) were purchased from (Sigma Aldrich, USA). Sulfuric acid (95\% - 97\%, MERCK, 1.00731, Germany), Mercury (II) sulfate (Riedel-de Haen, 31013, Germany), and De-ionized water were used to prepare all solutions.

\subsection{Instrumentation and Methods}

The free available chlorine was determined spectrophotometrically using $\mathrm{HACH}$ DR 1890 spectrophotometer. Ammonia, Chemical oxygen demand COD and nitrate were determined spectrophotometrically using UV-visible spectrophotometer (Perkin Elmer Lambda 10). Dissolved oxygen was measured using Oximeter with water bath (WTW-Inolab). Electric conductivity (EC) was measured using pH-EC-TDS meter (HI 9812, Hanna instruments). Turbidity and total suspended solids were measured using HACH DR\2010 Portable Data logging Spectrophotometer. COD, BOD, turbidity, total suspended solids and microbial counts were determined using standard procedures (APHA, 2006). The total organic carbon (TOC), inorganic carbon (IC), and total nitrogen (TN) was determined using TOC-VCPN coupled with TNM-1 module (Shimadzu Co). The Chromatographic separation of THMs was achieved using Gas chromatography mass spectroscopy (GC/MS). Wastewater samples were transferred quantitatively into a $10 \mathrm{~mL}$ headspace vial which was immediately sealed with a stainless steel screw cap with PTFE-lined septum. Vials were statically incubated at $95^{\circ} \mathrm{C}$ for 10 minutes in a COMPIPAL auto sampler (CTC Analytics AG, Switzerland). An aliquot $(1 \mathrm{~mL})$ of the headspace gas was subsequently withdrawn and injected into a 6890N Agilent GC combined with 5973 Agilent MS. Separation was performed on a Varian Factor Four TM capillary column (VF-5 ms, 30 m, 0.25 $\mathrm{mm}, 0.25 \mu \mathrm{m})$. The column oven temperature was held at $35^{\circ} \mathrm{C}$ for $5 \mathrm{~min}$ then ramped to $60^{\circ} \mathrm{C}$ at $10^{\circ} \mathrm{C} / \mathrm{min}$ and finally ramped to $200^{\circ} \mathrm{C}$ at $25^{\circ} \mathrm{C} / \mathrm{min}$. Injections were done in a pulsed split mode (split ratio 10 after $0.05 \mathrm{~min}$ of injection) with injector temperature at $220^{\circ} \mathrm{C}$. The transfer line and the ion source temperatures were maintained at $280^{\circ} \mathrm{C}$ and $230^{\circ} \mathrm{C}$, respectively. Selected ion mode (SIM) method was developed for four compounds (chloroform, bromodichloromethane, dibromochloromethane, bromoform) following USEPA 501 trihalomethane method. Quantification ions and method validation were performed with external standard calibration. Calibration curves in the concentration range from 2 to $100 \mu \mathrm{g} / \mathrm{L}$ were prepared from standard solution (Restek, Catalog \# 30211).

\subsection{Wastewater Treatment Plants}

Three wastewater treatment plants were selected to perform this study. Al-Quds University wastewater treatment plant (AQU P), which consists of a primary treatment unit (two stage primary settling basin), a secondary treatment unit 
(activated sludge with a hydraulic retention time of $16-20 \mathrm{~h}$, coagulation and chlorination stages) with capacity of $50 \mathrm{~m}^{3} /$ day. The secondary effluent is then filtered using sand filters before entering the ultrafiltration membrane which consists of a UF hollow fiber (HF) with $100 \mathrm{kD}$ cutoff filters as pre polishing stage for the UF spiral wound with $20 \mathrm{kD}$ cutoff filters. After ultrafiltration process, the effluent is filtered by activated carbon column followed by reverse osmosis, Diagram 1 shows Al-Quds wastewater treatment plant.

The Oasis hotel and resorts is the second wastewater treatment plant which is located on the south of Jericho city. Oasis WWTP (Oasis P) was built by TARMAC (1995) LTD, and started working in 1998 to treat around $800 \mathrm{~m}^{3} /$ day with peak flow rate around $60 \mathrm{~L} / \mathrm{sec}$ and 2 cycles per day. The main operational process is the biological treatment using two bioreactors. The first one is supplied by aerators which are the key factor to maintain the living bacterial biomass for biodegradation of the organic content. Water is then pumped to the second bioreactor which is a sequencing 5 -stepbatching reactor (SBR): filling, reacting, settling, decanting of clear supernatant effluent results after settling by gravity, and idle or disposal of sludge. Tertiary treated wastewater includes three sand filters. Chlorination is the final stage before going to storage tanks to kill bacteria and other potentially harmful microorganisms. Bio-oxidation system using fine bubble diffusers and dissolved oxygen control and monitoring, filtration up to the required level (115 micron) is achieved by using three layers of filtration media; basalt, quartz and anthracite followed by turbidity monitoring.

The third plant, Al-Uja WWTP (Auja P), it is located at Al-Uja village in Jericho, based on collection of grey wastewater from septic tanks followed by anaerobic pond, gravel filter as the primary filter and sand filter which contains shallow layer of stones, medium gravel, and pea gravel beneath a deep layer of sand and then constructed wet land that treats grey water in a reed bed system to reduce the organic load.

\subsection{Sampling, Chlorine Demand Experiments, and THMs Experiments}

\subsubsection{Wastewater Treatment Plants Samples}

Samples from influent of all WWTPs were taken during the experiments and effluents of Osais and Al-Auja WWTPs were taken, whereas four samples from secondary activated sludge treatment stage, Ultrafiltration included both (hollow fiber and spiral wound) and reverse osmosis units of Al-Quds WWTP effluents were taken for chemical, biological and physical characteristics.

\subsubsection{Chlorine Demand Experiments}

The ammonia concentration in non-chlorinated wastewater samples were measured before chlorination process. For ten brown one-liter bottles, $500 \mathrm{~mL}$ non filtrated wastewater samples were placed. Then chlorine solution was added with different concentration to achieve breakpoint curve. After chlorination, 30 minutes of incubation in dark place was done. The results of free available chlorine and ammonia were analyzed using HACH DR 1890. 


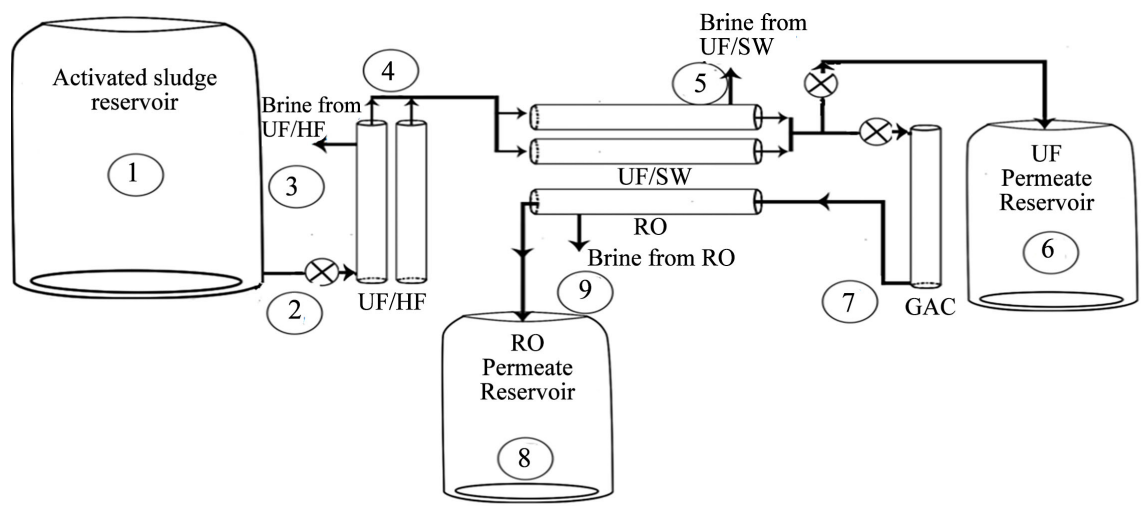

Diagram 1. Al-Quds university wastewater treatment plant which consists of UF-HF, UF-SW. Activated carbon and RO filters with possible effluents samples sites.

\subsubsection{Trihalomethanes Formation Potential (THMFP) Experiments}

Wastewater samples were taken from different wastewater treatment plants. 130 $\mathrm{mL}$ of each effluent is transferred to a brown glass bottle before chlorination, then excess constant chlorination were applied for each bottle. The bottles were incubated for $1,2,4,8,24,48,72,96,120$ hours, respectively. During and after five days incubation period, a $5 \mathrm{~mL}$ sample was taken as function of time and quenched by ascorbic acid to prevent further THMs formation potential. $\mathrm{pH}$ was adjusted to $7 \pm 0.3$ using $0.1 \mathrm{M} \mathrm{NaOH}$ and $0.1 \mathrm{M} \mathrm{HCl}$. Samples were kept under $25^{\circ} \mathrm{C}$ in an incubator in the dark. Samples were preserved in the refrigerator at $4^{\circ} \mathrm{C}$ for GC/MS analysis. All described experiments were conducted in triplicates.

\section{Results}

\subsection{Raw Wastewater Characteristics}

Raw and treated wastewater samples characteristics are summarized in Table 1. Raw wastewater characteristics of Al-Quds University Plant (AQU P) are classified as strong wastewater according to USEPA (2003) and PWA (2012) with $\mathrm{BOD}_{5} 850 \mathrm{mg} / \mathrm{L}$ concentration, COD $1853 \mathrm{mg} / \mathrm{L}$, TS $1492 \mathrm{mg} / \mathrm{L}$, TDS $970 \mathrm{mg} / \mathrm{L}$, TSS $492 \mathrm{mg} / \mathrm{L}$ and free ammonium $900 \mathrm{mg} / \mathrm{L}$. The secondary effluent for AQU P has a $\mathrm{BOD}_{5}$ of $600 \mathrm{mg} / \mathrm{L}$, TSS $145 \mathrm{mg} / \mathrm{L}$, and COD $1000 \mathrm{mg} / \mathrm{L}$. Raw wastewater characteristics of Oasis Plant (Oasis P) are classified as weak wastewater (USEPA, 2003) with $\mathrm{BOD}_{5} 74 \mathrm{mg} / \mathrm{L}$ concentration, COD $250 \mathrm{mg} / \mathrm{L}$, TS $917 \mathrm{mg} / \mathrm{L}$, TDS $730 \mathrm{mg} / \mathrm{L}$, TSS $187 \mathrm{mg} / \mathrm{L}$ and free ammonium $127 \mathrm{mg} / \mathrm{L}$. Raw wastewater characteristics of Auja Plant (Auja P) are classified as weak wastewater with $\mathrm{BOD}_{5}$ $178 \mathrm{mg} / \mathrm{L}$ concentration, COD $453 \mathrm{mg} / \mathrm{L}$, TS $935 \mathrm{mg} / \mathrm{L}$, TDS $640 \mathrm{mg} / \mathrm{L}$, TSS 295 $\mathrm{mg} / \mathrm{L}$ and free ammonia $89 \mathrm{mg} / \mathrm{L}$.

According to Memorandum of understanding on guidelines and technical criteria for sewerage projects signed between Israel and PWA (World Bank, 2004) treated effluent should not exceed $20 \mathrm{mg} / \mathrm{L}$ of BOD and $30 \mathrm{mg} / \mathrm{L}$ TSS for secondary treatment. Nonetheless, these values may be lower for tertiary treatment TSS $10 \mathrm{mg} / \mathrm{L}$ and BOD $10 \mathrm{mg} / \mathrm{L}$. In this study only RO effluents of AQU P achieved these limitations. 


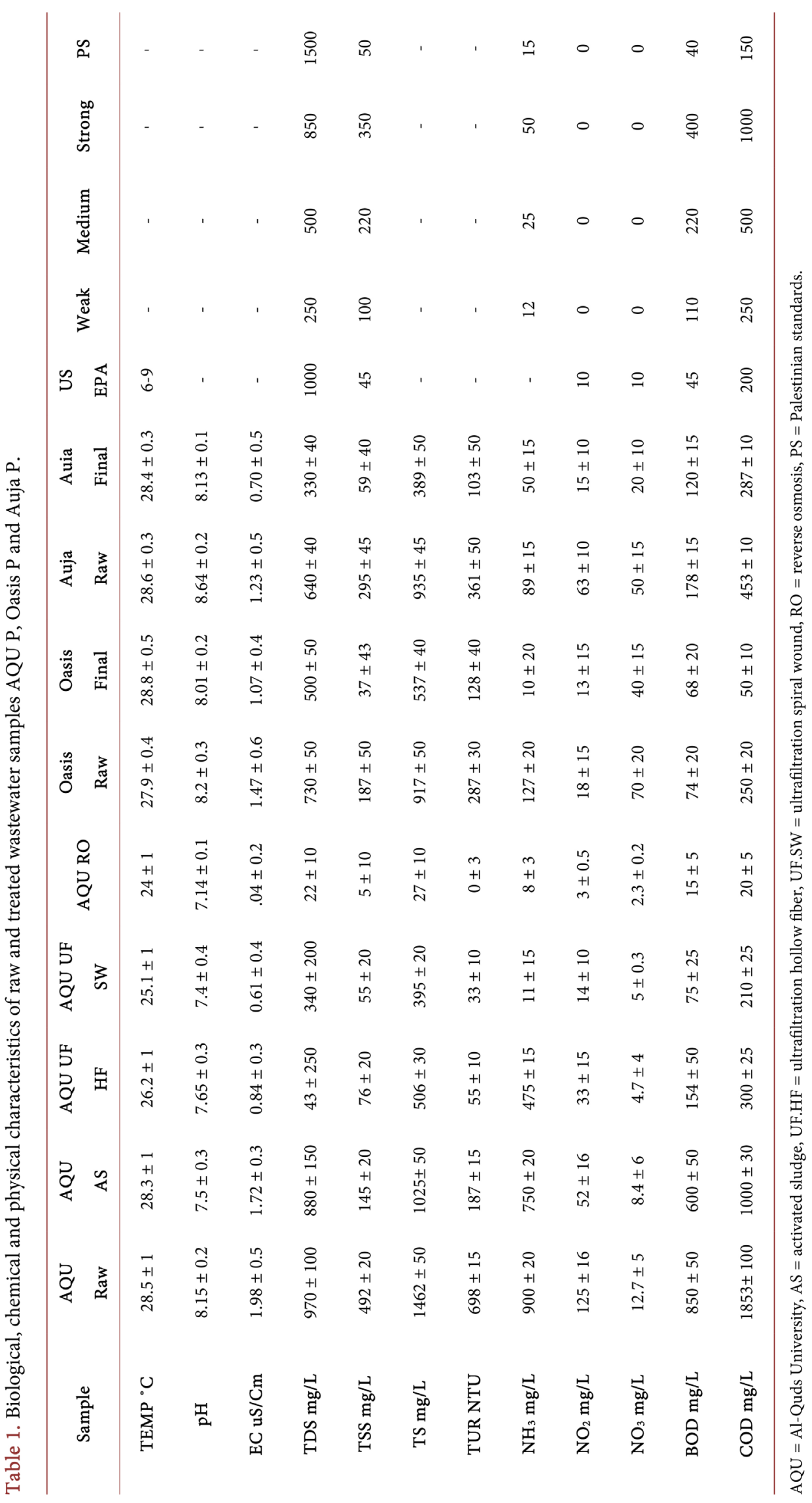




\subsection{Chlorine Demand}

In wastewater that contains ammonium, breakpoint chlorination is a means of eliminating ammonium to achieve true free chlorine residual [7]. The amount of chlorine consumed during these reactions is referred to as the chlorine demand that must be added to achieve a specific chlorine residual and proper disinfection [8].

Chlorine demand of treated wastewater samples was the highest $(1000 \mathrm{mg} / \mathrm{L})$ for treated wastewater samples from AQU P taken from activated sludge tank (Figure 1(a)). This high chlorine demand is an elevated dose related to concentrated organics and ammonia-N present in wastewater samples from treatment system. The chlorine demand in AS is considered as very high when compared with WHO standards which required $20 \mathrm{mg} / \mathrm{L}$ of chlorine for an activated sludge effluent [9].

On the other hand, less chlorine was required to satisfy the demand (Figure 1(b) \& Figure 1(c)) of treated samples of the first stage of advanced treatment membranes which are ultra-filtration hollow fiber and ultra-filtration spiral wound, respectively. The results show a reduction of ammonium concentration from $750 \mathrm{mg} / \mathrm{L}$ to around $113 \mathrm{mg} / \mathrm{L}$ in the effluent of UF-HF after passing through UF membranes which reduced chlorination demand as well. After the completion of the UF treatment stage the chlorine demand reached $150 \mathrm{mg} / \mathrm{L}$ and ammonium concentration of $11 \mathrm{mg} / \mathrm{L}$ due to more efficient treatment level than the AS stage. Figure 1(d) presents the chlorine demand results from the final stage of the advanced membrane technology RO in AQU P with the minimal concentration of chlorine demand, namely $20 \mathrm{mg} / \mathrm{L}$.

Treatment using membrane applications have more efficiency in chlorine demanding compounds [10]. The efficiency of RO systems in removal of ammonium, organic and nitrite nitrogen varies in the range of $60 \%$ to $90 \%$ [11]. RO has high efficiency in removing all ions of nitrogen [12]. Several researches have been conducted for an application of RO to remove nitrogenous compounds [13]. In AQU P RO effluents have the minimum ammonia concentration. The chlorine demand of treated wastewater from Oasis P (reactors 1 and 2) are shown in Figure 2(a) and Figure 2(b). The initial ammonium concentration in Oasis $\mathrm{P}$ is approximately $32 \mathrm{mg} / \mathrm{L}$. This drooped after the bioreactor 2-stage of treatment to reach approximately $10 \mathrm{mg} / \mathrm{L}$.

Auja treatment plant is a simple primitive one that receives gray water. Figures 3(a)-(d) present Auja P ammonia and chlorine inverse relationship. The initial concentration of ammonium in tank 3 is approximately $75 \mathrm{mg} / \mathrm{L}$ and ends in the effluent to be $50 \mathrm{mg} / \mathrm{L}$ in the final tank, with chlorine demand around 300 $\mathrm{mg} / \mathrm{L}$ in both influent and effluent. Hence, no obvious treatment and reduction in ammonium concentration is noticed in this treatment system. Pant and Mittal (2007) study showed that the smaller the concentration of ammonium in wastewater before chlorination, the more free chlorine that could be generated for a fixed dose of chlorine. This occurred in Auja tank 7 and final tank with FAC 
reaches to around $5 \mathrm{mg} / \mathrm{L}$.

Some references provide a guideline stating when free residual chlorine is a 93\% - 95\% of total residual chlorine then breakpoints are achieved but such principles can be misleading (White et al., 1986). To assure that chlorination is beyond breakpoint, ammonium should be zero or very near to zero [14] [15]. In this study all wastewater samples, ammonium was removed by chlorine and reached to zero $\mathrm{mg} / \mathrm{L}$. When chlorine is added, FAC start showing up gradually in small concentrations less than $1 \mathrm{mg} / \mathrm{L}$, until ammonia reached to zero $\mathrm{mg} / \mathrm{L}$ at this point $\mathrm{FAC}$ increases proportionally and reaches to 5 $\mathrm{mg} / \mathrm{L}$.

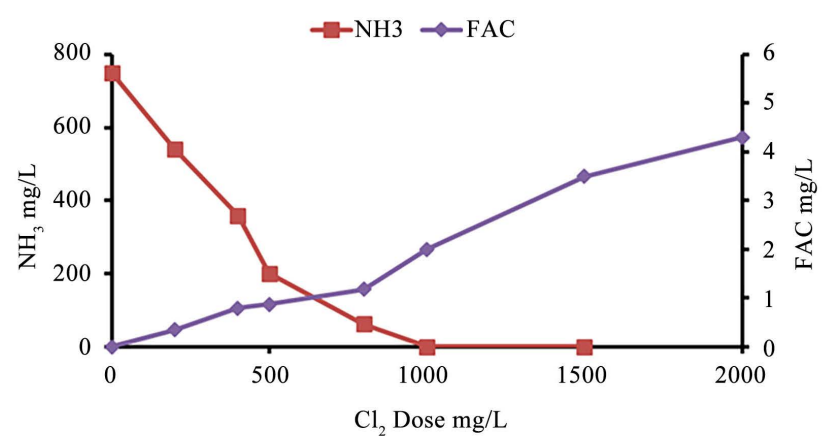

(a)

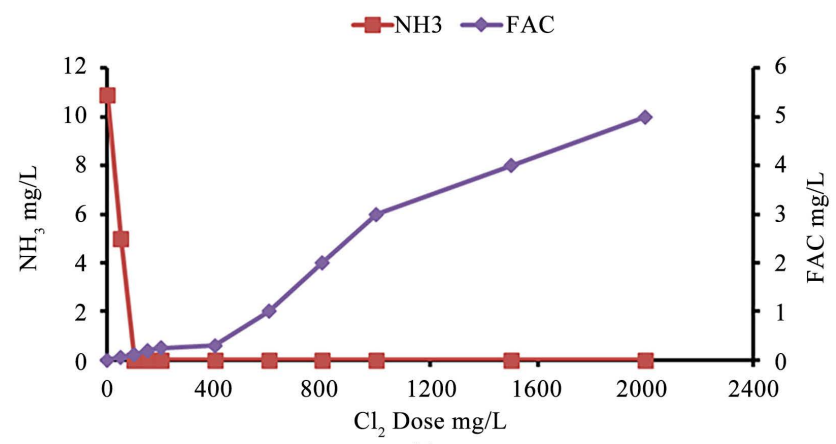

(c)

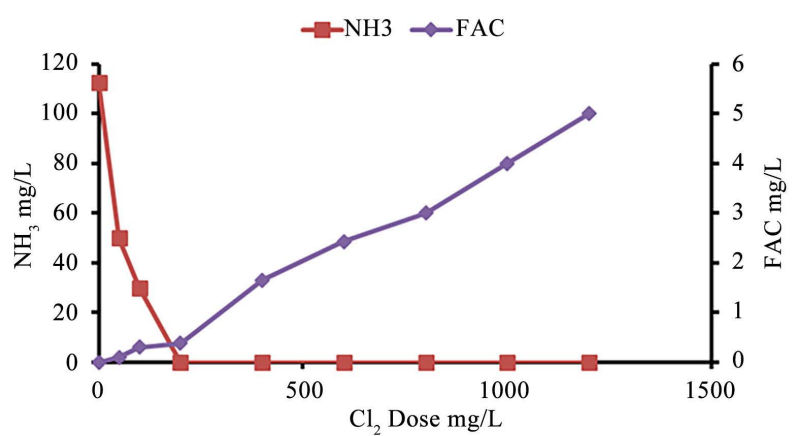

(b)

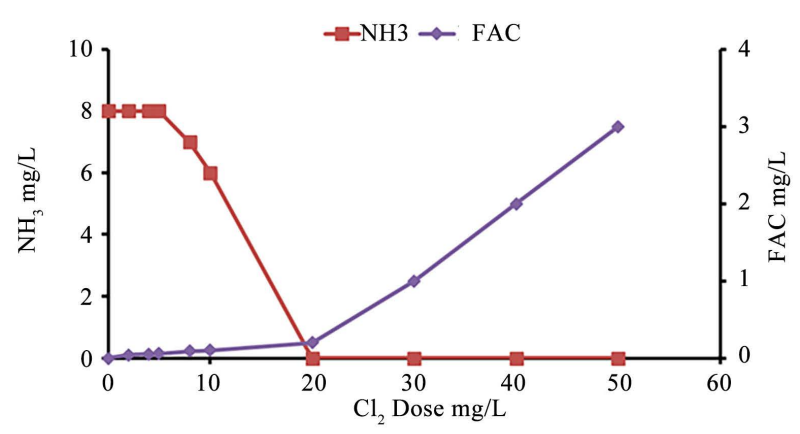

(d)

Figure 1. (a) Chlorine demand and ammonium concentration for an activated sludge samples; (b) Chlorine demand and ammonium concentration for ultrafiltration hollow fiber samples; (c) Chlorine demand and ammonium concentration for ultrafiltration spiral wound samples; (d) Chlorine demand and ammonium concentration for reverse osmosis samples.

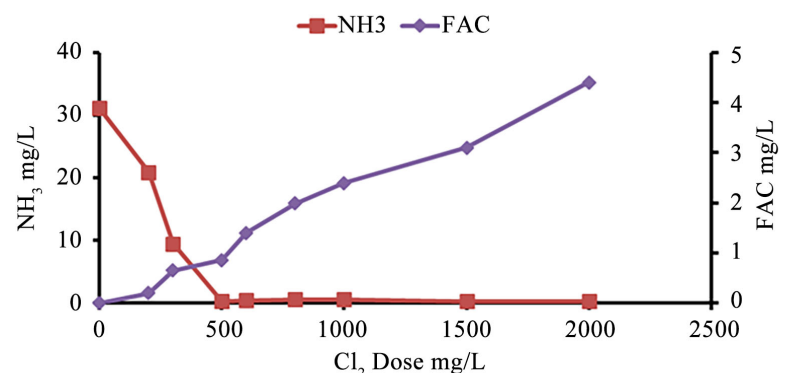

(a)

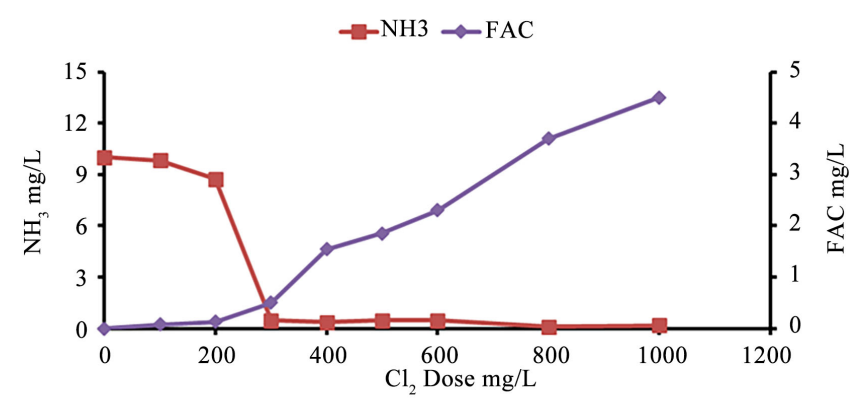

(b)

Figure 2. (a) Chlorine demand and ammonium concentration for oasis bioreactor 1 samples; (b) Chlorine demand and ammonium concentration for oasis bioreactor 2 samples. 


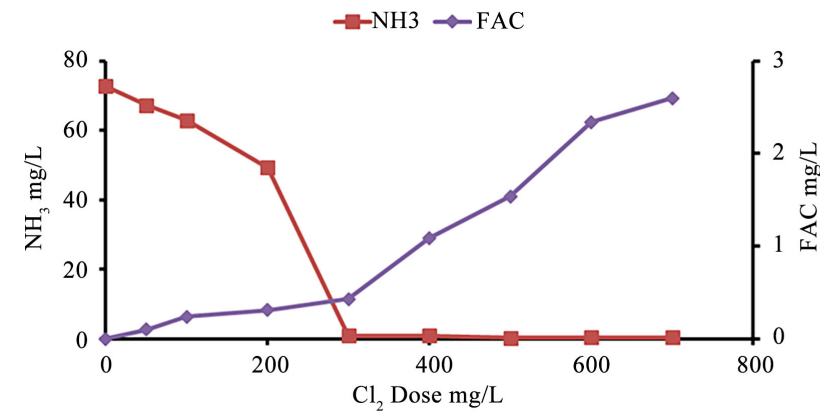

(a)

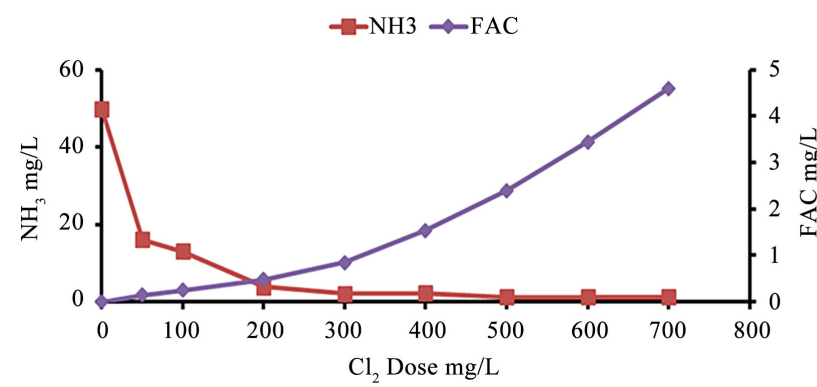

(c)

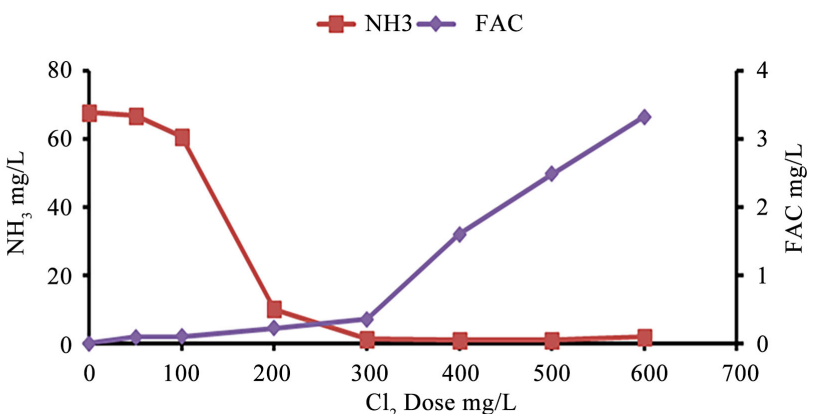

(b)

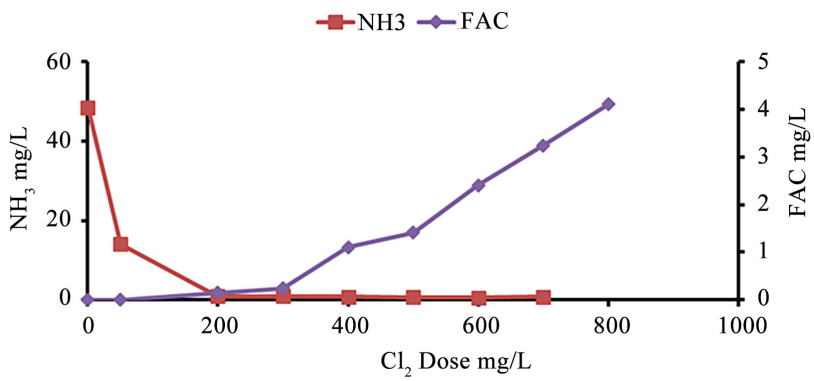

(d)

Figure 3. (a) Chlorine demand and ammonium concentration for Auja tank 3 samples; (b) Chlorine demand and ammonium concentration for Auja tank 5 samples; (c) Chlorine demand and ammonium concentration for Auja tank 7 samples; (d) Chlorine demand and ammonium concentration for Auja final tank samples.

The difference in ammonium levels affects breakpoint results [16] [17]. This happens in tested wastewater samples from three wastewater treatment plants that shows different ammonium concentrations and varied in chlorine demand as indicated earlier.

In all cases and samples the general inverse relationships between ammonium and free chlorine is well shown in Figures 1-3. Ammonium in wastewater reacts with free chlorine to generate more chloramines (or combined chlorine residual). Thus, the smaller the concentration of ammonium in wastewater treatment system prior to chlorination, the more free chlorine that could be generated for a fixed dosage of chlorine [14].

\subsection{Trihalomethanes Formation Potentials (THMFP)}

Variations in TTHM depend on the quantity and characteristics of organic matter, chlorine dose and contact time, $\mathrm{pH}$, and temperature. Higher THMs arise from higher precursor levels, temperatures, dosage rates and reaction times [18]. TTHFP of different treatment scenarios from AQU $P$ are shown in Figures 4(a)-(c). Generally, chloroform (CF) is seen to dominate THM species. TTHMs consist of CF occupying 96\% of TTHMs and BDCM occupying only $3.5 \%$ from AS samples. It is obvious that TTHM concentrations increased over the incubation period. Species such as dibromochloromethane (DBCM) and bromoform (BF) aren't detected or were below $1 \mu \mathrm{g} / \mathrm{L}$ due to low or no detection of bromide in source water.

The major THMs species in UF of AQU P are CF and BDCM. TTHMs mainly 
consist of CF occupies 84\% and BDCM occupies 15\%. Again the major THMs species in RO of AQU P are CF and BDCM (Figure 4(b)) CF occupies $90 \%$ of TTHMs while BDCM is around 9.5\% of TTHMs.

The major THMs species in Oasis P are CF and BDCM (Figure 4(d)) shows the dominance of CF over BDCM, DBCM and BF in Oasis samples. CF reaches to $936 \mu \mathrm{g} / \mathrm{L}$ while BDCM ends up to $333 \mu \mathrm{g} / \mathrm{L}$, thus TTHMs mainly have CF $69 \%$ and BDCM 22\%. However, other species as DBCM and BF are detected but with lower concentrations $6 \%$ and $1 \%$ respectively. Brominated species appeared in

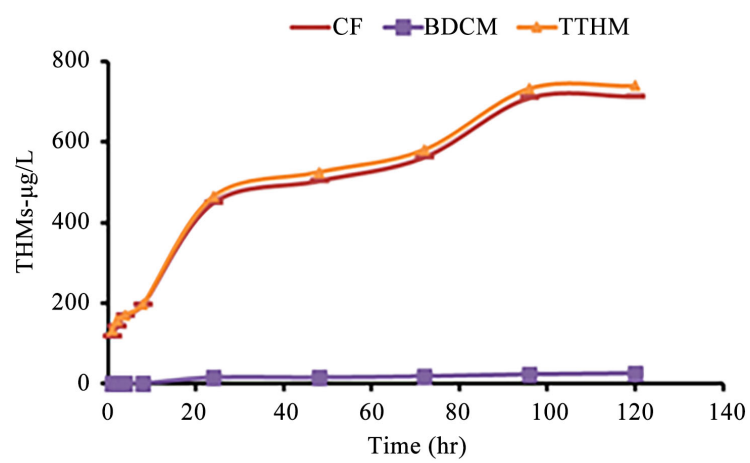

(a)

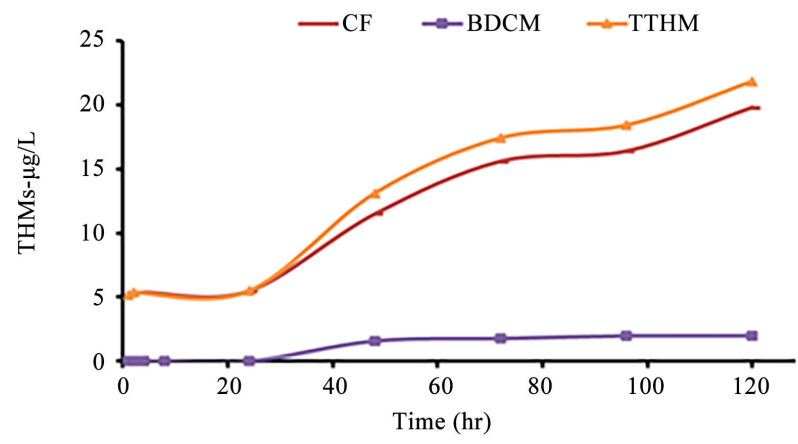

(c)

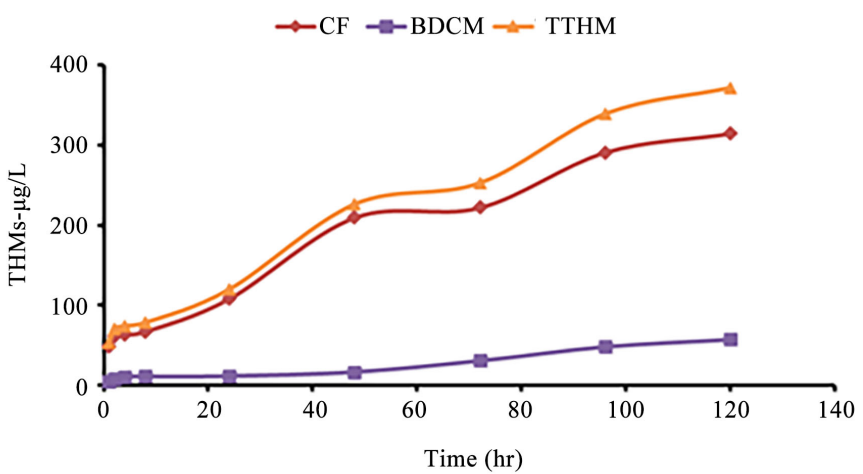

(b)

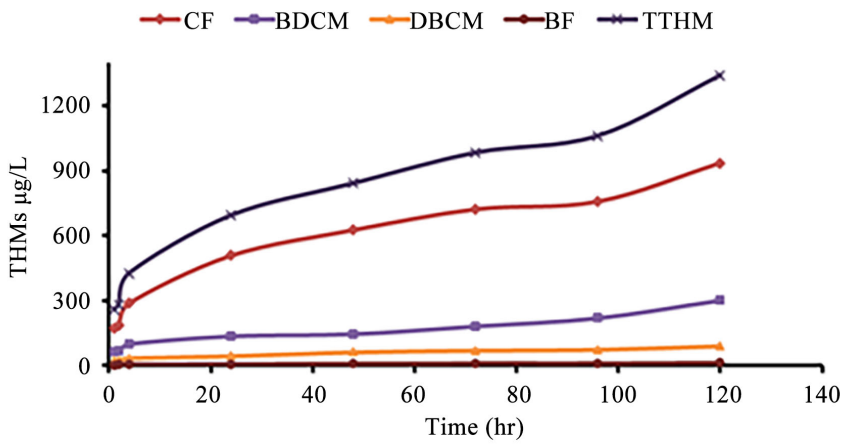

(d)

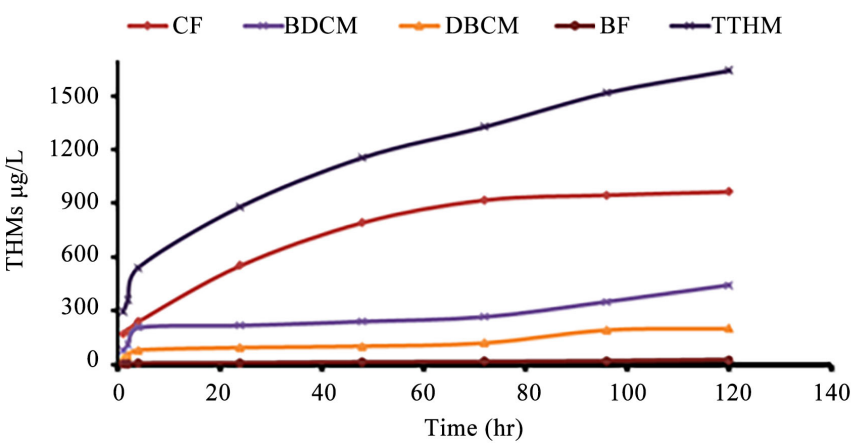

(e)

Figure 4. (a) Chlororform (CF), Bromodichloromethane (BDCM) and TTHMs results for activated sludge effluent (AS) of AQU P; (b) Chloroform (CF), bromodichloromethane (BDCM) and TTHMs for ultrafiltration effluent of AQU P; (c) Chloroform (CF), bromodichloromethane (BDCM) and TTHMs for reverse osmosis effluent of AQU P; (d) Chloroform (CF), bromodichloromethane (BDCM), dibromochloromethane (DBCM), bromoform (BF) and TTHM (total trihalomethanes) for Oasis P; (e) Chloroform (CF), bromodichloromethane (BDCM), dibromochloromethane (DBCM), bromoform (BF) and TTHM (total trihalomethanes) for Auja P. 
Oasis P since bromide is present in water source in Jericho [19]. If chlorine and bromine is present during chlorination, chlorine will act as oxidant while bromine becomes a halogenating agent because bromine atoms preferred substitution during formation of halogenated DBPs.

The major THMs species in Auja P are CF and BDCM (Figure 4(e)) again with chloroform dominating over other species. TTHMs mainly consist of $58 \%$ CF and 27\% BDCM however other species as 12\% DBCM and 1.7\% BF are detected but with lower percentage. Brominated species are detected in Oasis $\mathrm{P}$ and Auja P since the presence of bromide [19] in the source water from Jericho [20].

\section{Discussion}

AQU P receives large amounts of wastewater from different sources of AQU campus, including laboratories' chemical and organic wastes and kitchens due to large population of the campus and from rain water. Oasis $\mathrm{P}$ has weak wastewater since amount of receiving wastewater and type is different. Oasis is a hotel that has different type of wastewater entering the treatment plant. Moreover, Auja $\mathrm{P}$ receives only grey water which is reflected on relatively low ammonia concentration. As a result, the breakpoint chlorine dosages and the patterns of the breakpoint curves varied among the samples from three WWTPs.

Chlorine is a non-selective oxidant and will therefore react with both organic and inorganic substances in wastewater in different degrees [21]. Chlorine consumption is controlled essentially by the type and quantities of these constituents mainly: ammonia concentration [11], and variations in raw water quality and treatment processes described earlier justifies the variation in chlorine demand results. In Palestine the level of chlorine residuals in drinking water must be maintained in the range of 0.2 to $1 \mathrm{mg} / \mathrm{L}$ to prevent microbial contamination of distribution system [22] but there is no specific standard for wastewater chlorination.

The TTHMFP from all wastewater treatments are compared and shown in Figure 5. In general AQU P produced the lowest amount of TTHMs as compared to Oasis P and Auja P. This could be interpreted by the difference in organic precursors and the presence of bromide in the background water coming from water source as mentioned before although TOC were not with same order for the three plants (TOC results are not shown).

WHO regulated chloroform not to exceed $200 \mu \mathrm{g} / \mathrm{L}$ in drinking water, USEPA assigned $80 \mu \mathrm{g} / \mathrm{L}$ for TTHMs, and the European Union (EU) determined 100 $\mu \mathrm{g} / \mathrm{L}$ for TTHMs [9]. Unfortunately, specific standards are not available for treated wastewater used for agriculture irrigation, except for the maximum permissible chloroform concentration in soils receiving untreated municipal wastewater which is approximately $0.47 \mathrm{mg} / \mathrm{kg}$ [17]. TTHMFPs exceeded these drinking water guidelines and standards. Some municipal wastewater treatment plants in New Jersey established limits for trihalomethanes after wastewater chlorination; for chloroform 221, BDCM 3.3, DBCMB 2.4 and bromoform $26 \mu \mathrm{g} / \mathrm{L}$ 


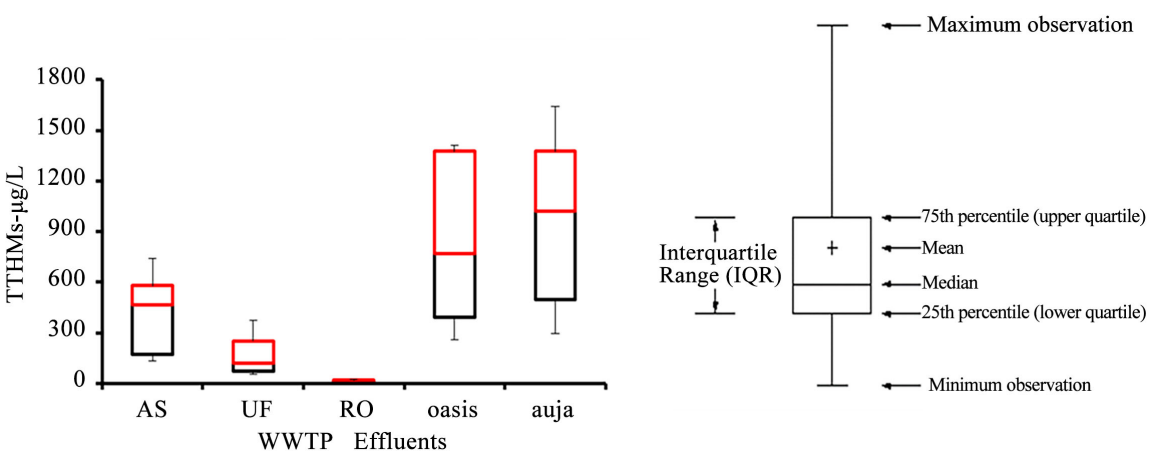

Figure 5. TTHMFP from AQU P (Activated Sludge (AS), Ultrafiltration (UF), Reverse Osmosis (RO)), Oasis P, and Auja P treated effluents.

[23]. In this study only RO effluents didn't exceed the limits of CF and BDCM. However, all others produced more than these limits. In the finished wastewater effluent from all plants, chloroform was the dominant THM compound. In Oasis $\mathrm{P}$ and Auja $\mathrm{P}$ the dominant brominated THM was BDCM; which is the second most important THM species after bromoform from toxicological point view and health effects analysis [24]. Nevertheless, the levels of this compound are low.

According to the Environmental Protection Agency (EPA), trihalomethanes (THMs) are among the most dangerous chemical compounds into water supply [25]. THMs occur when the water disinfectants, chlorine and chloramines, react with naturally occurring organic or inorganic material. THM contamination is very common as byproduct formed during disinfection process of drinking water. Presence of THMs in drinking water is known as carcinogenic. Unfiltered chlorinated water can be very toxic. Consuming THMs such as drinking unfiltered chlorinated water or exposing the body to the shower can cause absorbing THMs by skin and inhale it as gas, which can directly enter the bloodstream. The exposure to drinking water contain of (0.77 - $1.25 \mathrm{ppb})$ can cause esophageal, liver and kidney cancer. [26] [27]. The THMs byproduct of chlorinated water has been associated with spontaneous abortion, birth defects and low birth weight [28]-[35].

Producing THM in drinking water can be avoided bya change in water disinfection strategy, people using chlorination strategy due to an economic reason, is considered to be cheaper than other known methods, and not because it is the best method. Therefore using chlorine dioxide, ozone, copper or silver ionization, hydrogen peroxide, and UV can be an alternative strategy, to avoid formation of THM in dirking water or a combination between two methods can be an excellent alternative method challenge is to remove any organic material, which can be a source to THM before chlorination. This can be done by applying reverse osmosis system, and unfortunately this process can remove the naturally occurring minerals from water, and wasting considerable amount of water during this process. If avoiding chlorination during water disinfection process is impossible, it is suggested to use multistage filtration steps using a house filter packaged with activated carbon, and C-18 silica gel, to avoid any contamination 
of drinking water by THM or any volatile organic compounds (VOCs) or any organic contaminants. The use of multistage filter will remove more than $97 \%$ of such toxic materials.

Trihalomethans (THM) contain bromide atom show high reactivity and lipophilicity, which affected tissue solubility and other physiological issues. Mink and co-workers [36] show that BDCM dissolved by corn oil attained strong absorption to the mice tissue. Moreover, $93 \%$ of the dose was recovered as carbon dioxide, the unmetabolized parent compound was distribute as $2.2 \%$ in urine and $3.2 \%$ in organs. Liver, stomach and kidney were the organ, which have been effected by such pollutant. Mathews and co-worker [37] show that $1 \%-3 \%$ of the THM dose with at least one bromide atom accumulates in liver, and other significant amount of the dose accumulate on the cortical regions of kidney. The spread of hepatic \& renal diseases in the Palestinian area from where the samples collected, indicate that the freshwater and the one used in agriculture infected strongly by organic compounds and VOC, which cause formation of THM during chlorination disinfection step. The spread of cancer disease \&Newborn congenital anomalies in region where the samples was collected can be explained by consuming such water by drinking, use for cleaning or in the agriculture activity. It is well established that THM compounds can easily absorbed in human tissues by drinking or absorbed by skin or by breathing. Tomasi, Gao \& coworkers [38] [39] show that THMs especially the one contain bromide atom can very easily metabolized into phosgene and formation of dihalomethyl free radical as very active species.

Glutathione (GSH) is an important antioxidant in living cells. It plays a very crucial role in preventing important cellular damage by reactive species such as oxygen, peroxide, heavy metals and free radicals [40]. Consuming water contain THM can inhibit the function of GSA in human body and animals according to the mechanism shown in (Scheme 1). The conjugation of GSA undergo via nucleophilic substitution to THM or by thioesterification of the GSA with metabolized THM (phosgene), the consumption of GSA will lead to damage of important cellular component.

Metabolized THM through oxidation condition will lead to formation of phosgene, which is considered an extremely reactive chemical species, which can form in presence of biomaterials the following groups: carbonodithioate, carbonothioate, carbonate, carbamate and carbamothioate. The consequence of the reaction between phosgene and biomaterials, will lead to denaturation of proteins, peptides [41], and damage DNA double strand to mono strand (Scheme 1). Moreover, the reduction of THM species can occur on iron atom in hemoglobin. This generates a very reactive radical species, which can perform more damage to molecular cellular components.

All the reaction performed by THM in the cell, will definitely lead to mutation of many proteins, and RNA wrong signal a cause to DNA damage, which will lead to diseases like cancer, and Newborn congenital anomalies similar to the causes registered near these sources of water where this study took place [42]. 


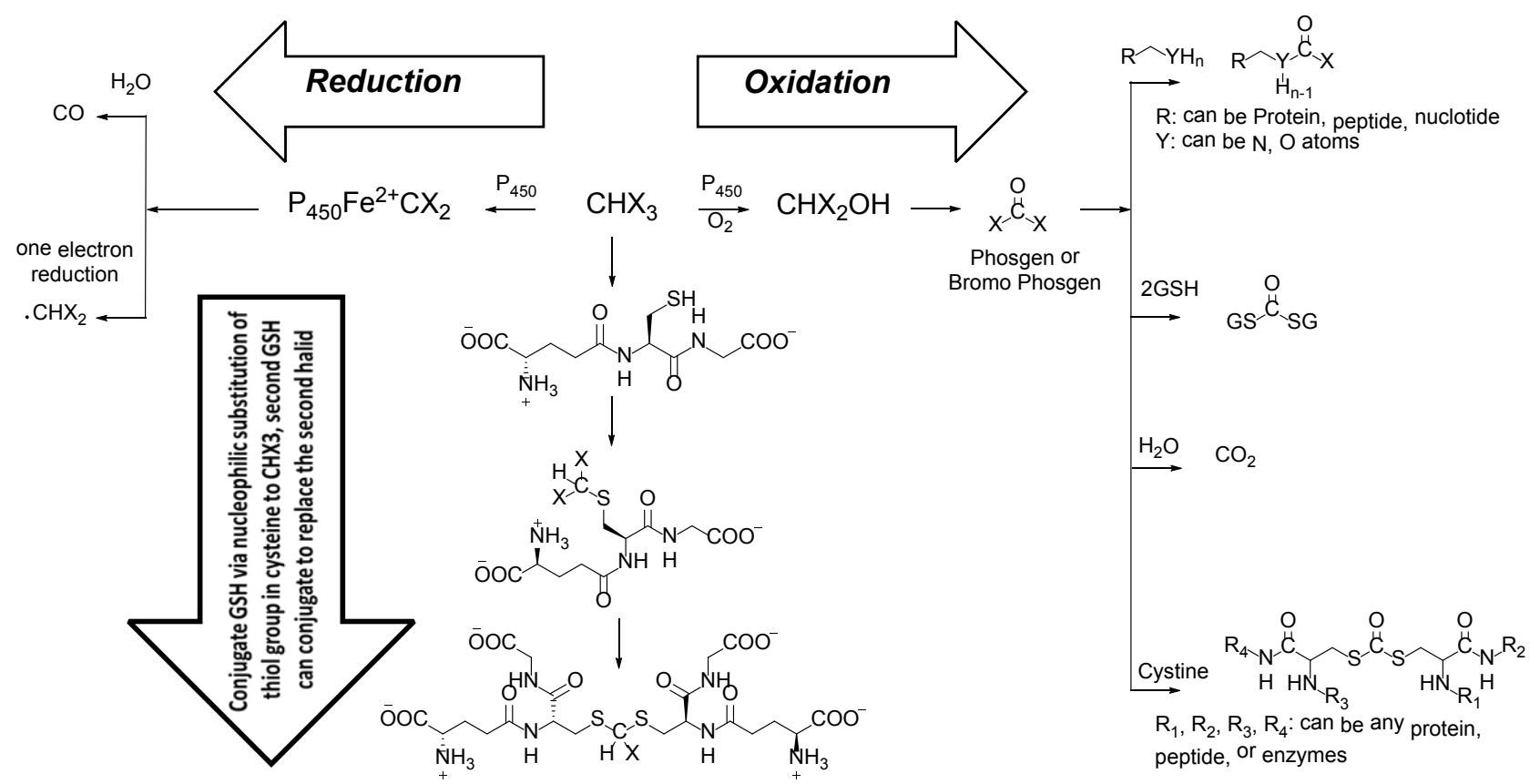

Scheme 1. The trihalomethanes THM reactions, the oxidations reaction can lead to formation of very dangers species (phosgene) which can react with many molecular cellular components, the reduction of THM can form very reactive radical species which can damage the biomaterials. THM can react by nucleophilic substitution reaction.

\section{Conclusion}

This study of water and wastewater is being carried out in selective areas where high percentage of Newborn congenital anomalies, cancer, hepatic \& renal diseases cases occurred. It showed that THM can be considered as a major cause. The influence of the chlorination process to water will lead to series damage to molecular cellular component. Removal of such species and all organic compounds from water required an extra filtration step before using this water for drinking purposes or in any agricultural irrigation activity. The best way is to pass the water through reversed phase silica gel filter (C18-filter), or any other filter like activated carbon, which can capture organic materials. This step can remove all the dangerous organic components like THM from water and make it safer to use.

\section{Acknowledgements}

Authors will like to thanks Al-Quds University for helping in implementation this work.

\section{References}

[1] Glauner, T., et al. (2005) Swimming Pool Water-Fractionation and Genotoxicological Characterization of Organic Constituents. Water Research, 39, 4494-4502. https://doi.org/10.1016/j.watres.2005.09.005

[2] Bixio, D., et al. (2008) Water Reclamation and Reuse: Implementation and Management Issues. Desalination, 218, 13-23. https://doi.org/10.1016/j.desal.2006.10.039 
[3] Bdour, A.N., Hamdi, M.R. and Tarawneh, Z. (2009) Perspectives on Sustainable Wastewater Treatment Technologies and Reuse Options in the Urban Areas of the Mediterranean Region. Desalination, 237, 162-174. https://doi.org/10.1016/j.desal.2007.12.030

[4] Singer, P.C. and Chang, S.D. (1989) Correlations between Trihalomethanes and Total Organic Halides Formed during Water Treatment. Journal of American Water Works Association, 1989, 61-65. https://doi.org/10.1002/j.1551-8833.1989.tb03260.x

[5] Adams, C., et al. (2005) Trihalomethane and Haloacetic Acid Disinfection By-Products in Full-Scale Drinking Water Systems. Journal of Environmental Engineering, 131, 526-534. https://doi.org/10.1061/(ASCE)0733-9372(2005)131:4(526)

[6] Kanan, A. and Karanfil, T. (2011) Formation of Disinfection By-Products in Indoor Swimming Pool Water: The Contribution from Filling Water Natural Organic Matter and Swimmer Body Fluids. Water Research, 45, 926-932.

https://doi.org/10.1016/j.watres.2010.09.031

[7] McDonald, J. (2003) Breakpoint Chlorination Plays Important Role in RO Pretreatment. Ultrapure Water, 20, 36-40.

[8] Palin, A. (1974) Chemistry of Modern Water Chlorination. Water Services, 78, 7-12.

[9] WHO (2005) Regional Overview of Wastewater Management and Reuse in the Eastern Mediterranean Region. World Health Organization, Regional Office for the Eastern Mediterranean Regional, California Environmental Health Association.

[10] Hsu, Y.-C., et al. (2012) Survey on Production Quality of Electrodialysis Reversal and Reverse Osmosis on Municipal Wastewater Desalination. Water Science and Technology, 66, 2185-2193. https://doi.org/10.2166/wst.2012.445

[11] Chen, B., Kim, Y. and Westerhoff, P. (2011) Occurrence and Treatment of Wastewater-Derived Organic Nitrogen. Water Research, 45, 4641-4650.

[12] Metcalf, E. and Eddy, E. (2003) Wastewater Engineering: Treatment and Reuse. McGraw Hill Inc., New York.

[13] Agus, E. and Sedlak, D.L. (2010) Formation and Fate of Chlorination By-Products in Reverse Osmosis Desalination Systems. Water Research, 44, 1616-1626.

[14] Arana, I., et al. (1999) Chlorination and Ozonation of Waste-Water: Comparative Analysis of Efficacy through the Effect on Escherichia coli Membranes. Journal of Applied Microbiology, 86, 883-883. https://doi.org/10.1046/j.1365-2672.1999.00772.x

[15] Cotruvo, J., Craun, G.F. and Hearne, N. (1999) Providing Safe Drinking Water in Small Systems: Technology, Operations, and Economics. CRC Press, Boca Raton.

[16] Sivakamasundari, N., et al. (2014) Optrode Based Polymer for the Estimation of Free Chlorine. Applied Mechanics \& Materials, 573, 856-860. https://doi.org/10.4028/www.scientific.net/AMM.573.856

[17] Organization, W.H. (2006) Guidelines for the Safe Use of Wastewater, Excreta and Greywater. World Health Organization, Vol. 1.

[18] Sirivedhin, T. and Gray, K.A. (2005) Comparison of the Disinfection By-Product Formation Potentials between a Wastewater Effluent and Surface Waters. Water Research, 39, 1025-1036.

[19] Marie, A. and Vengosh, A. (2001) Sources of Salinity in Ground Water from Jericho Area, Jordan Valley. Groundwater, 39, 240-248.

https://doi.org/10.1111/j.1745-6584.2001.tb02305.x 
[20] Chowdhury, S., Champagne, P. and McLellan, P.J. (2010) Investigating Effects of Bromide Ions on Trihalomethanes and Developing Model for Predicting Bromodichloromethane in Drinking Water. Water Research, 44, 2349-2359.

[21] White, G.C. (2010) White's Handbook of Chlorination and Alternative Disinfectants. Wiley, Hoboken.

[22] Authority, P.W. (2012) Status Report of Water Resources in the Occupied State of Palestine-2012. Technical Report, Annual Water Resources Status Report.

[23] Patoczka, J., Tyrrell, P. and Wynne, M. (2011) THMs Control in Wastewater Treatment Plant Effluent. Proceedings of the Water Environment Federation, 3, 189-198. https://doi.org/10.2175/193864711802863526

[24] Ding, G., et al. (2013) Formation of New Brominated Disinfection Byproducts during Chlorination of Saline Sewage Effluents. Water Research, 47, 2710-2718.

[25] Victoria, E. (2003) Guidelines for Environmental Management: Use of Reclaimed Water. EPA, Victoria.

[26] Tsai, S.-S., Chiu, H.-F. and Yang, C.-Y. (2013) Trihalomethanes in Drinking Water and the Risk of Death from Esophageal Cancer: Does Hardness in Drinking Water Matter? Journal of Toxicology and Environmental Health, Part A, 76, 120-130. https://doi.org/10.1080/15287394.2013.738410

[27] Liao, Y.H., et al. (2012) Trihalomethanes in Drinking Water and the Risk of Death from Kidney Cancer: Does Hardness in Drinking Water Matter? Journal of Toxicology and Environmental Health Part A: Current Issues, 75, 340-350.

[28] Ruddick, J., et al. (1983) A Teratological Assessment of Four Trihalomethanes in the Rat. Journal of Environmental Science \& Health Part B, 18, 333-349. https://doi.org/10.1080/03601238309372373

[29] Thompson, D., Warner, S. and Robinson, V. (1974) Teratology Studies on Orally Administered Chloroform in the Rat and Rabbit. Toxicology and Applied Pharmacology, 29, 348-357. https://doi.org/10.1016/0041-008X(74)90107-0

[30] Murray, F., et al. (1979) Toxicity of Inhaled Chloroform in Pregnant Mice and Their Offspring. Toxicology and Applied Pharmacology, 50, 515-522. https://doi.org/10.1016/0041-008X(79)90406-X

[31] Kanitz, S., et al. (1996) Association between Drinking Water Disinfection and Somatic Parameters at Birth. Environmental Health Perspectives, 104, 516. https://doi.org/10.1289/ehp.96104516

[32] Kramer, M.D., et al. (1992) The Association of Waterborne Chloroform with Intrauterine Growth Retardation. Epidemiology, 3, 407-413. https://doi.org/10.1097/00001648-199209000-00005

[33] Bove, F.J., et al. (1995) Public Drinking Water Contamination and Birth Outcomes. American Journal of Epidemiology, 141, 850-862. https://doi.org/10.1093/oxfordjournals.aje.a117521

[34] Gallagher, M.D., et al. (1998) Exposure to Trihalomethanes and Adverse Pregnancy Outcomes. Epidemiology, 9, 484-489. https://doi.org/10.1097/00001648-199809000-00003

[35] Savitz, D.A., Andrews, K.W. and Pastore, L.M. (1995) Drinking Water and Pregnancy Outcome in Central North Carolina: Source, Amount, and Trihalomethane Levels. Environmental Health Perspectives, 103, 592. https://doi.org/10.1289/ehp.95103592

[36] Mink, F., et al. (1983) In Vivo Formation of Halogenated Reaction Products Following Peroral Sodium Hypochlorite. Bulletin of Environmental Contamination 
and Toxicology, 30, 394-399. https://doi.org/10.1007/BF01610150

[37] Mathews, J., Troxler, P. and Jeffcoat, A. (1990) Metabolism and Distribution of Bromodichloromethane in Rats after Single and Multiple Oral Doses. Journal of Toxicology and Environmental Health, Part A Current Issues, 30, 15-22. https://doi.org/10.1080/15287399009531406

[38] Tomasi, A., et al. (1985) Activation of Chloroform and Related Trihalomethanes to Free Radical Intermediates in Isolated Hepatocytes and in the Rat in Vivo as Detected by the ESR-Spin Trapping Technique. Chemico-Biological Interactions, 55, 303-316. https://doi.org/10.1016/S0009-2797(85)80137-X

[39] Gao, P., Thornton-Manning, J.R. and Pegram, R.A. (1996) Protective Effects of Glutathione on Bromodichloromethane in Vivo Toxicity and in Vitro Macromolecular Binding in Fischer 344 Rats. Journal of Toxicology and Environmental Health, 49, 145-159. https://doi.org/10.1080/009841096160899

[40] Pompella, A., et al. (2003) The Changing Faces of Glutathione, a Cellular Protagonist. Biochemical Pharmacology, 66, 1499-1503. https://doi.org/10.1016/S0006-2952(03)00504-5

[41] Awad, L., et al. (2016) A New Caged-Glutamine Derivative as a Tool to Control the Assembly of Glutamine-Containing Amyloidogenic Peptides. Chembiochem, 17, 2353-2360. https://doi.org/10.1002/cbic.201600474

[42] Center, P.H.I. (2017) Health Annual Report, Palestine 2016. Ministry of Health, Palestine. 